\title{
AN ATYPICAL, BRACHYPTEROUS SPECIES OF IDRIS FÖRSTER (PLATYGASTROIDEA: SCELIONIDAE) FROM INDIA*
}

\author{
Veenakumari, Kamalanathan $^{1 *}$ and Prashanth Mohanraj ${ }^{1,2}$ \\ ${ }^{1} I C A R-N a t i o n a l$ Bureau of Agricultural Insect Resources \\ P.B. No. 2491, Hebbal, Bengaluru, India 560024 \\ E-mails: ${ }^{1}$ veenapmraj@gmail.com; https://orcid.org/0000-0002-1039-6761 \\ ${ }^{2}$ veenaprashi@rediffmail.com; https://orcid.org/0000-0001-7089-3957
}

A new species of Idris - Idris semiflaviventris sp. n. - belonging to the tribe Baeini is described from Kodaikanal in the Western Ghats, South India. This species is unusual in that it has a short interocellar space, subequal posterior margins of T1 and T2, and T2 the longest and widest tergite.

Keywords: Baeini, brachyptery, mesoscutellum, T2, T3, spider, taxonomy, Hymenoptera.

\section{INTRODUCTION}

The tribe Baeini (Scelionidae) are specialist endoparasitoids of spider eggs (IQbal \& Austin 1997). Idris elba Talamas, recently found parasitizing the eggs of Bagrada hilaris (Burmeister) (Hemiptera: Pentatomidae) (LomeliFlores et al. 2019), is the only species that does not conform to the utilization of Araneidae as ovipositional hosts. Of the 12 genera in Baeini (sensu Austin 1986, Austin \& Field 1997), the three most speciose are Idris Förster (including Ceratobaeus Ashmead as junior synonym with 325 species), Baeus Haliday (91 species) and Odontacolus Kieffer (55 species) (Austin \& Field 1997, Johnson et al. 2018, Veenakumari et al. 2020). While Odontacolus are apparently confined to the tropical and subtropical regions, the other two genera are ubiquitous in their distribution (JoHnson et al. 2018).

Recent molecular studies by CAREY et al. (2006) reveal that Baeini (sensu Austin 1986, Austin \& Field 1997) is polyphyletic and not monophyletic as previously thought, the included species switching twice to spider hosts within the Scelionidae.

Idris was erected by FöRsTER (1856) based on male specimens, with I. flavicornis as the type species. Simultaneously he erected another genus Acolus with female specimens, oblivious of the fact that they were sexual dimorphs of the congeneric Idris (MASNer 1961, Huggert 1979). It was only in 1961 that Masner, taking cognizance of this, synonymized these two genera. HuggerT (1979) detailed the convoluted synonymic history of these genera in his revision of Idris and Ceratobaeus of the West Palaearctic region.

*urn:1sid:zoobank.org:pub:C5053C0D-7175-4F59-9BE2-86344ADA68BB 
Species of the tribe Baeini, in general, has a wide range of wing size morphology. It can be found individuals with macropterous (large, fully functional wings) through brachypterous (small, non-functional wings, reduced to less than a third of their normal size) to micropterous (reduced, non-functional, flap-like remnants of wings). It is only the former two states that are found in species of Idris with the majority of them being macropterous, while some are brachypterous (CAREY et al. 2006, Huggert 1979). Abbreviated wings and a wide body in some Baeini are surmised to be two adaptations enhancing their ability to burrow through leaf litter to locate the silken egg sacs to parasitize the eggs of spiders (Austin et al. 2005). Eight of the twenty species reported by HugGerT (1979) from the Western Palaearctic exhibit sex-specific brachyptery with only the females being brachypterous and males (of known species) macropterous. Of these eight species, three, viz., I. flavicornis Förster, I. piceiventris (Kieffer) and I. semicastaneus (Kieffer) have brachypterous wings of variable lengths from short to extending just beyond T2 to macropterous. The Western Palaearctic females, however, do not have wide or expanded bodies. Austin et al. (2005) believe that except for a couple of non-Australian Idris and Ceratobaeus wing reduction appears to be species-specific.

Thirty of the 325 species of Idris reported from the world occur in India (Johnson 1992, Rajmohana 2006, 2014, Veenakumari et al. 2015, Johnson et al. 2018, Hol 2019) all of which are macropterous. Only two species groups, the melleus-species group (Masner \& Dennis 1996) and the adikeshavus- species group (Veenakumari et al. 2015) have so far been defined in the effort to bring order to this vast genus. Creation of region-wise species groups will further help in this direction when cataloguing the species diversity of this disparate mega-genus.

Unlike the species detailed above, a new atypical species of Idris characterized by wing reduction in both sexes coupled with a wide body is described in this paper.

\section{MATERIAL AND METHODS}

Colour images were obtained using a Leica M205A stereomicroscope, with $1 \times$ objective and Leica DFC-500 digital camera with LED ring light illuminator. The images were stacked using Leica Application Suite (LAS) software. All specimens used for SEM studies were mounted on SEM stubs, and images were captured using Hitachi Table top microscope TM3030 (ESEM: Environmental Scanning Electron Microscope). The specimen was attached using two-sided conductive adhesive copper tape to the aluminium stub. No metal or carbon coating was applied. No dehydration treatments were used in the variable pressure vacuum system (VPSEM/environmental SEM). The same specimen could be carefully reoriented on the stub to obtain images of different parts enabling retrieval of the specimens. Measurements were taken during the imaging process.

Terminology for morphology follows Masner $(1976,1980)$, Miкó et al. $(2007,2010)$ and that for macro and microsculpture HARRIs (1979). The following abbreviations are 
used in the description of the taxa. L - length; W - width; A1-A12 - antennomeres 1-12; IOS - interorbital space; T1-T3 - metasomal tergites 1-3. Width of all metasomal tergites taken anteriorly. All the measurements are taken following the method of Miкó et al. (2010).

All the specimens were collected using yellow pan traps (YPT).

The type specimens of the new species are deposited in the ICAR-National Bureau of Agricultural Insect Resources (ICAR-NBAIR), Bengaluru, India.

\section{TAXONOMY}

\section{Idris semiflaviventris Veenakumari sp. $\mathrm{n}$ * $^{*}$}

(Figs 1-6)

Material examined: Holotype, female (ICAR/NBAIR/P2693), INDIA: Tamil Nadu: Kodaikanal, Shenbaganur, $10^{\circ} 14^{\prime} 01^{\prime \prime} \mathrm{N} 77^{\circ} 30^{\prime} 47^{\prime \prime} \mathrm{E}, 1865 \mathrm{~m}, \mathrm{YPT}, 02 . I V .2014$. Paratypes: 1 female, (ICAR/NBAIR/P2694), same data as holotype; 2 males, (ICAR/NBAIR/P2695, P2696), same data as holotype.

Description: Female body length $=0.98 \mathrm{~mm}(\mathrm{~m}=0.93(0.88-0.98) \mathrm{mm}, \mathrm{n}=2)$. Male body length $=0.83 \mathrm{~mm}(\mathrm{~m}=0.85(0.83-0.86) \mathrm{mm}, \mathrm{n}=2)$.

Colour (Figs 1 \& 3): Head, mesosoma and T1 dark brownish black; remainder of metasoma yellowish brown; antenna brownish black; coxa, femur and anterior 3/4th of tibia blackish brown and remainder of leg brownish black.

Head (Figs 1, 2, 5 \& 6): Vertex and dorsal mesonotum covered with dense short white setae; head $1.23 \times$ as wide as high and $1.3 \times$ as high as long; IOS very short, $0.3 \times$ width of head, $0.57 \times$ eye length; dorsal frons rugose, antennal scrobe distinct on either side of central keel; vertex rugose; gena densely striate; anterior and posterior margins of gena parallel and converging dorsally; POL > LOL in ratio of 20.2:15.4; posterior ocelli contiguous with orbits; distance between hyperoccipital carina and posterior margin of lateral ocellus $<0.4 \times$ MOD; posterior margin of eye touching hyperoccipital carina, densely setose, subequal in length and width; interantennal process rugose, protruding; facial striae and malar striae distinct; A1 and clava subequal in length; A2 3.1× as long as A3; A3 subequal in length and width; clava $2 \times$ as long as wide.

Mesosoma (Figs 1, 5 \& 6): Mesoscutum and mesoscutellum $0.65 \times$ and $0.57 \times$ as long as wide respectively; both mesoscutum and mesoscutellum with same sculpture as that on vertex; notauli absent; lateral pronotal area dorsally rugose, remainder predominantly smooth with sparse weak transverse carinae posteriorly; subacropleural sulcus and mesepimeral sulcus foveate, speculum with deep furrows; mesopleural pit and mesopleural carina distinct; ventral mesopleuron smooth with a rugose patch medially; ventral margin of mesopleuron extending as a narrow structure; metapleuron dorsally with transverse carinae, remainder smooth except for foveate metapleural sulcus posteriorly; paracoxal sulcus indicated as a furrow; posterior margin of mesoscutellum ' $\mathrm{V}$ ' shaped, extending over anterior margin of $\mathrm{T} 1$ hiding metascutellum and medial propodeum; posterior mesoscutellar sulcus foveate; propodeum triangular with vertical carinae, visible dorsolaterally, with postero-lateral corners extending as a spine; fore wing sclerite narrow extending up to T1.

Metasoma (Figs 1, 5 \& 6): Metasoma $0.82 \times$ as long as wide; T1 distinctly visible dorsally and strongly costate, with a triangular granular patch laterally; T2 with anterior onethird costate; the remainder of T2 and other tergites with granular sculpture; T2 longest *urn:lsid:zoobank.org:act:ABC05E92-840B-4AFE-B01D-76AA070549E7 


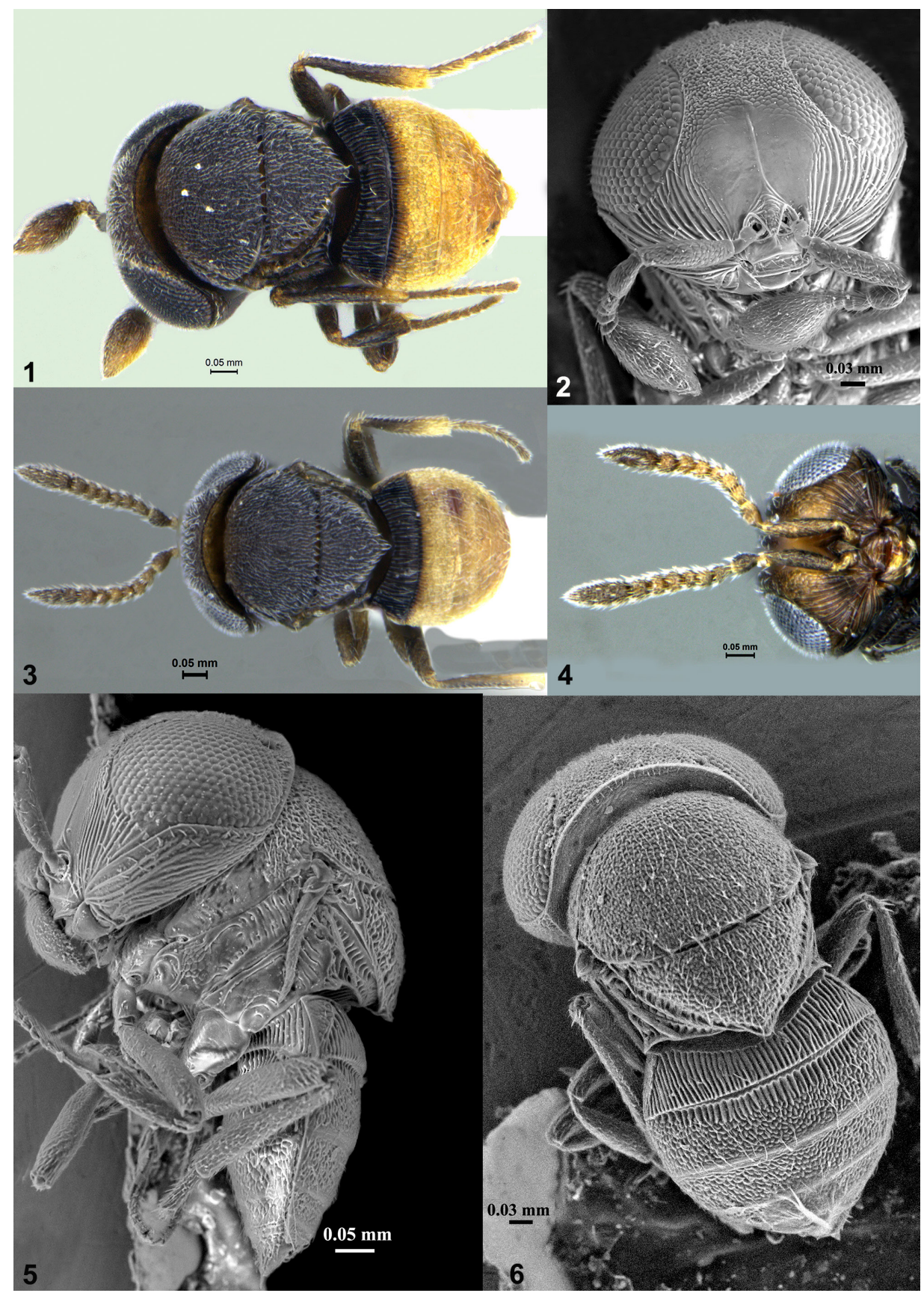

Figs 1-6. Idris semiflaviventris sp. n.: 1 = habitus, dorsal view (female), 2 = head (female), $3=$ habitus, dorsal view (male), 4 = head (male), 5 = habitus lateral view (female), $6=$ habitus dorsal view (female) 
and widest of all tergites; posterior margins of T1 and T2 subequal; T2 $1.4 \times$ as long as T3; T2 $0.25 \times$ as long as the width of its anterior margin; submarginal ridge well impressed.

Male (Figs 3 \& 4): Similar to female. Antenna moniliform with nine visible antennomeres unlike that generally found in males of Idris which have 12 antennomeres where the last two antennomeres are either fused or have a distinct constriction between them.

Etymology: The species epithet 'semiflaviventris' refers to the yellow color of T2 and remaining tergites in both sexes. The name is treated as an adjective.

Diagnosis: Idris semiflaviventris sp. n. is unique among all the species of Idris so far described because of the following combination of character states: both male and female are brachypterous; T2 longer than T3 (except I. adikeshavus species group); posterior margins of T1 and T2 subequal; IOS narrow, at most $0.3 \times$ head width; male antenna with nine visible antennomeres. This combination of character states is not present in any other described species of Idris.

However, this species resembles two Indian species, I. triangularis Mukerjee and I. coorgensis (Mani et Mukerjee) in having a posteriorly extended mesoscutellum. The salient differences between $I$. semiflaviventris and the other two species are T2 longest and widest of all tergites, posterior margin of T1 and T2 subequal; IOS short, at most $0.3 \times$ head width in I. semiflaviventris sp. $\mathrm{n}$. while in the other two species T3 longer and wider than T2, posterior margin of T1 narrower than posterior margin of T2, IOS at least $0.6 \times$ head width.

Idris triangularis is macropterous; central keel on frons extending up to anterior ocellus; mesoscutum and mesoscutellum finely reticulate and shiny; T2 entirely costate; whereas I. semiflaviventris sp. $\mathrm{n}$. is brachypterous, central keel on frons extending half the length of frons; mesoscutum and mesoscutellum rugose; T2 anteriorly costate and posteriorly rugose.

Idris coorgensis was described based on a male specimen. This species is also macropterous; notaulus present; male antennomeres A11 and A12 with distinct constriction; mesoscutum and mesoscutellum finely reticulate; T2 entirely costate; whereas I. semiflaviventris sp. n. is brachypterous; notaulus absent; male antennae with 9 visible antennomeres; mesoscutum and mesoscutellum rugose; T2 anteriorly costate and posteriorly rugose.

Acknowledgements - The authors are grateful to the Director, ICAR-NBAIR, Bengaluru and the Director, ICAR-IIHR, Bengaluru for providing facilities and encouragement. We are grateful to Dr. L. Masner for taxonomic discussion. We thank Dr. M. Krishna Reddy, Dr. D. K. Samuel, Ms. K. Bharathi and Mr. K. Balasubramani (T-5) of the Division of Plant Pathology, ICAR-IIHR, Bengaluru for the SEM images. We thank B. L. Lakshmi, V. Shashikala, B. Vinod and Roopa for their support both in the field and laboratory. We are indebted to Hymenoptera online for literature support. Two anonymous reviewers are also acknowledged. 


\section{REFERENCES}

Austin, A. D. (1986): A taxonomic revision of the genus Mirobaeoides Dodd (Hymenoptera, Scelionidae). - Australian Journal of Zoology 34: 315-337. https://doi.org/10.1071/ ZO9860315

Austin, A. D. \& Field, S. A. (1997): The ovipositor system of scelionid and platygastrid wasps (Hymenoptera: Platygastoidea): comparative morphology and phylogenetic implications. - Invertebrate Taxonomy 11: 1-87. https://doi.org/10.1071/IT95048

Austin, A. D., Johnson, N. F. \& Dowton, M. (2005): Systematics evolution and biology of scelionid and platygastrid wasps. - Annual Review of Entomology 50: 553-582. https:// doi.org/10.1146/annurev.ento.50.071803.130500

Carey, D., Murphy, N. P. \& Austin, A. D. (2006): Molecular phylogenetics and the evolution of wing reduction in the Baeini (Hymenoptera: Scelionidae): parasitoids of spider eggs. - Invertebrate Systematics 20: 489-501. https://doi.org/10.1071/IS06011

Harris, R. A. (1979): A glossary of surface sculpturing. - Occasional Papers in Entomology 28: $1-31$.

Huggert, L. (1979): Revision of the west Palaearctic species of the genus Idris Foerster, s.l. (Hymenoptera: Proctotrupoidea: Scelionidae). - Entomologica Scandinavica 12(Supplement): $1-60$.

Iqbal, M. \& Austin, A. D. (1997): Species richness and endemism of baeine wasps (Hymenoptera: Scelionidae) in Australia. - Memoirs of Museum Victoria 56: 455-459. https:// doi.org/10.24199/j.mmv.1997.56.38

Johnson, N. F. (1992): Catalog of world Proctotrupoidea excluding Platygastridae. - Memoirs of the American Entomological Institute 51: 1-825.

Johnson, N. F., Chen, H. \& Huber, B. A. (2018): New species of Idris Förster (Hymenoptera, Platygastroidea) from southeast Asia, parasitoids of the eggs of pholcid spiders (Araneae, Pholcidae). - Zookeys 811: 65-80. https://doi.org/10.3897/zookeys.811.29725

Lomeli-Flores, J. R., Rodríguez-Rodríguez, S. E., Rodríguez-Levya, E., GonzálezHernández, H., Gariepy, T. D. \& Talamas, E. J. (2019): Field studies and molecular forensics identify a new association: Idris elba Talamas, sp. nov. parasitizes the eggs of Bagrada hilaris (Burmeister). - Journal of Hymenoptera Research 73: 125-141. https:// doi.org/10.3897/jhr.73.38025

Masner, L. (1961): The genera Gryon Hal., Idris Forst. and Hemisius Westw. (Hym. Scelionidae). - Casopis Ceskoslovenske Spolecnosti Entomologicke 58:157-168.

MAsner, L. (1976): Revisionary notes and keys to world genera of Scelionidae (Hymenoptera: Proctotrupoidea). - Memoirs of the Entomological Society of Canada 108: 1-87. https://doi.org/10.4039/entm10897fv

MAsner, L. (1980): Key to genera of Scelionidae of the Holarctic region, with descriptions of new genera and species (Hymenoptera: Proctotrupoidea). - Memoirs of the Entomological Society of Canada 112: 1-54. https://doi.org/10.4039/entm112113fv

Masner, L. \& Dennis, J. (1996): The Nearctic species of Idris Foerster. Part 1: The melleusgroup (Hymenoptera: Scelionidae). - The Canadian Entomologist 128: 85-114. https:// doi.org/10.4039/Ent12885-1

Mikó, I., Vilhelmsen, L., Johnson, N. F., Masner, L. \& Pénzes, Zs. (2007): Skeleto-musculature of Scelionidae (Hymenoptera: Platygastroidea) head and mesosoma. - Zootaxa 1571: 1-78. https://doi.org/10.11646/zootaxa.1571.1.1

Mikó, I., Masner, L. \& DeAns, A. R. (2010): World revision of Xenomerus Walker (Hymenoptera: Platygastroidea, Platygastridae). - Zootaxa 2708: 1-73. https://doi. org/10.11646/zootaxa.2708.1.1 
Rajmohana, K. (2006): A checklist of Scelionidae (Platygastroidea: Hymenoptera) from India. - Zoos Print 21(12): 2506-2513. https://doi.org/10.11609/JoTT.ZPJ.1570.2506-13

Rajmohana, K. (2014): A systematic inventory of Scelioninae and Teleasinae (Hymenoptera: Platygastridae) in the rice ecosystems. - Memoirs of the Zoological Survey of India 22(1): 1-72, XXIV pls.

Various Contributors (2019): Hymenoptera online (HOL). [accessed August 2019]. http:// hol.osu.edu.

Veenakumari, K., Prashanth Mohanraj \& Khan, F. R. (2015): 'The adikeshavus-group': A new species group of Idris Förster (Hymenoptera, Platygastridae) from India, with descriptions of five new species. - Deutsche Entomologische Zeitschrift 62(2): 247-260. https://doi.org/10.3897/dez.62.6219

Veenakumari, K., Prashanth Mohanraj, Samuel, D. K. \& Krishna Reddy, M. (2020): Revision of Indian species of Baeus Haliday (Hymenoptera: Platygastroidea: Scelionidae). - Journal of Natural History 54(13-14): 816-917. https://doi.org/10.1080/00222933.2020.1770885

Received August 27, 2020, accepted November 15, 2020, published February 22, 2021 
